\title{
EFICIÊNCIA OPERACIONAL NO DESDOBRO DE Pinus UTILIZANDO MODELOS DE CORTE NUMA SERRARIA DE PEQUENO PORTE
}

\author{
Alberto António Manhiça1 ${ }^{1}$ Márcio Pereira da Rocha², Romano Timofeiczyk Junior ${ }^{3}$
}

(recebido: 6 de novembro de 2010; aceito: 25 de janeiro de 2013)

RESUMO: Nesta pesquisa, pretendeu-se avaliar uma metodologia de desdobro de toras que envolve a classificação destas e estabelecimento de modelos de corte para diferentes classes diamétricas aplicadas em um programa de computador MaxiTora visando à otimização no desdobro de toras. Para tal, foram selecionadas 80 toras de Pinus sp com diâmetros que variaram de 24 $\mathrm{cm}$ a $33 \mathrm{~cm}$, formando quatro classes diamétricas com 20 toras por classe. Em cada classe diamétrica, as toras foram separadas em dois lotes com 10 unidades, onde no primeiro lote todas as toras foram misturadas e submetidas ao desdobro convencional e o segundo lote, com as classes devidamente separadas, submetidas ao desdobro programado, de acordo com a simulação obtida no programa para cada classe. Para cada tora, foi cronometrado o tempo efetivo de desdobro até que a última peça de madeira fosse refilada. Para o sistema de desdobro convencional, a eficiência operacional alcançada variou de 9,71 a $11,22 \mathrm{~m}^{3} / \mathrm{operário/turno} \mathrm{e} \mathrm{a}$ média geral correspondeu $10,18 \mathrm{~m}^{3}$ operário/turno. No sistema de desdobro programado, a eficiência operacional alcançada variou de 7,78 a $8,99 \mathrm{~m}^{3} /$ operário/turno, e a média geral correspondeu a $8,07 \mathrm{~m}^{3} /$ operário/turno. Os valores da eficiência no desdobro de toras aumentaram com o aumento do diâmetro da tora, mantendo constantes outros fatores como o tempo de desdobro. A eficiência média geral da serraria, alcançada, em decorrência do desdobro programado, foi menor em relação à eficiência média geral alcançada com o desdobro convencional. A eficiência da serraria, alcançada no desdobro programado, foi reduzida, pela falta de experiência dos operadores das máquinas.

Palavras-chave: Desdobro de toras, simulação, eficiência operacional.

\section{OPERATIONAL EFFICIENCY IN SAWING Pinus USING CUTING MODELS IN SMALL SCALE SAWMILL}

\begin{abstract}
This research evaluated a methodology of cutting logs that involves both their classification and the establishment of cutting models for different diametrical classes. The software MaxiTora was employed aiming the optimization of cutting logs. A total of 80 logs of Pinus sp had been selected with diameter that varied from $24 \mathrm{~cm}$ to $33 \mathrm{~cm}$, gathering four diametrical classes with 20 logs each. In each diametrical class, the logs had been separate in two lots with 10 units, where the first lot was submitted to conventional cutting and the second lot was submitted to the programmed cutting. For each log the effective time of cut was recorded until the last lumber piece was edged. For the conventional cutting system, the efficiency reached from the same cutting system varied from 9.71 to $11.22 \mathrm{~m}^{3}$ operator.day and the general average corresponded to $10.18 \mathrm{~m}^{3} /$ operator/day. In the programmed cutting system, the efficiency reached through the same cutting system varied from 7.78 to $8.99 \mathrm{~m}^{3} /$ operator.day, while the general average corresponded the $8.07 \mathrm{~m}^{3} /$ operator.day. The general average efficiency achieved in the programmed sawing process was smaller in relation to general average efficiency obtained with conventional sawing process. The sawing efficiency achieved in the programmed sawing process was reduced due to the lack of experience of machine operators.
\end{abstract}

Key words: Cut of logs, simulation, operational, efficiency.

\section{INTRODUÇÃO}

O Brasil, com aproximadamente 6,5 milhões de hectares plantados, é um dos países com maior área ocupada com plantios florestais no mundo e ocupa a $11^{\underline{a}}$ posição mundial como produtor de madeira serrada de florestas plantadas, predominando as espécies dos gêneros Pinus e Eucalyptus (ASSOCIAÇÃO BRASILEIRA DE
PRODUTORES DE FLORESTAS PLANTADAS ABRAF, 2012). A madeira proveniente desses plantios destina-se, principalmente, à produção de papel e celulose, painéis de madeira, madeira serrada, carvão vegetal, energia industrial.

O pinus constitui uma das essências florestais mais utilizadas no Brasil, na indústria de madeira processada mecanicamente. A região sul do país concentra maior parte

\footnotetext{
${ }^{1}$ Engenheiro Florestal, Pesquisador Mestre Em Engenharia Florestal - Instituto de Investigação Agrária de Moçambique/IIAM - Centro de Investigação Florestal/CIF - Cx. P. 268 - Marracuene, Moçambique - albertomanhica@yahoo.com.br

${ }^{2}$ Engenheiro Florestal, Professor Doutor em Engenharia Florestal - Universidade Federal do Paraná/UFPR - Setor de Ciências Agrárias - Departamento de Engenharia e Tecnologia Florestal - Av. Prefeito Lothario Meissner, 3400, Jardim Botânico - 80210-170 - Curitiba, PR, Brasil - mprocha@ufpr.br ${ }^{3}$ Engenheiro Florestal, Professor Doutor em Engenharia Florestal - Universidade Federal do Paraná/UFPR - Setor de Ciências Agrárias - Departamento de Economia Rural e Extensão - Av. Prefeito Lothario Meissner, 900, Jardim Botânico - 80210-170 - Curitiba, PR, Brasil - romano@ufpr.br
}

Cerne, Lavras, v. 19, n. 2, p. 339-346, abr./jun. 2013 
dessas florestas, sendo os Estados do Paraná e de Santa Catarina detentores da maior área plantada com o pinus (ASSOCIAÇÃO BRASILEIRA DA INDÚSTRIA DE MADEIRA PROCESSADA - ABIMCI, 2007).

Entretanto, é comum encontrar na região sul, várias serrarias pequenas processando a madeira de pinus usando um equipamento lento e técnicas não adequadas. A operação de desdobro é dependente da experiência do operador da máquina principal na visualização de todas as alternativas na tora de acordo com as suas características (diâmetro e defeitos) para a tomada de decisão visando à retirada de peças de madeira para atender ao objetivo da empresa. Essa atitude, na maioria das vezes, resulta em níveis relativamente baixos na eficiência operacional de produção de madeira serrada.

A eficiência de conversão de toras em madeira serrada pode afetar amplamente serrarias que processam a madeira de florestas plantadas de rápido crescimento, pois, trata-se de toras de pequenas dimensões e homogêneas, requerendo elevada produção na serraria, em razão do baixo valor do produto final. A eficiência constitui uma das ferramentas fundamentais para avaliar o desempenho da serraria nas operações de desdobro.

É importante ressaltar que no cálculo da eficiência na serraria é usado o volume de toras para que o diâmetro da tora e o rendimento não influenciem no resultado obtido (ROCHA, 2002). A eficiência indica a demanda de toras de uma serraria, importante para o planejamento de suas operações. No entanto, de um modo geral, a eficiência é afetada por alguns fatores como a madeira (espécie, dureza e presença de defeitos), técnicas de desdobro, operador (número e experiência), lay-out da serraria, características e condições dos equipamentos, grau de automação da serraria, etc. (ROCHA, 2002; TSOUMIS, 1991).

Haygreen e Bowyer (1982) relatam que o grande avanço para aumentar os níveis da eficiência em serrarias está relacionado com a aplicação de scanners eletrônicos acoplados a um computador para a varredura do perfil da tora (diâmetro, comprimento e forma) e posicionamento da mesma em relação à serra principal para a localização do corte de abertura.

Adicionalmente, Williston (1978) faz referência que os scanners permitem avaliar a geometria da tábua e definem a melhor posição da mesma de modo que ao passar pela refiladeira, alcancem o máximo aproveitamento. Para o mesmo autor, a inclusão dos scanners no lay-out combinados ao computador, resulta, também, em um aumento surpreendente dos rendimentos em madeira serrada.

Cerne, Lavras, v. 19, n. 2, p. 339-346, abr./jun. 2013
Batista e Carvalho (2007) conduziram uma pesquisa com o objetivo de avaliar o desempenho de uma serraria de pequeno porte, estudando o tempo gasto na produção, rendimento e eficiência no desdobro de Eucalyptus spp. Os autores encontraram valores de rendimento e eficiência correspondentes a 44,86\% e 4,96 $\mathrm{m}^{3} /$ operário/turno, respectivamente.

Rocha (2002) apresenta uma classificação com valores de eficiência em serrarias de algumas regiões do mundo, mencionando que serrarias automatizadas do Brasil alcançam uma eficiência entre 20 a $50 \mathrm{~m}^{3} /$ operário/dia; serrarias comuns, entre 5 a $10 \mathrm{~m}^{3} /$ operário/ dia; serrarias norte-americanas e européias, acima de 50 $\mathrm{m}^{3} /$ operário/dia; serrarias do Amazonas atingem $0,3 \mathrm{~m}^{3} /$ operário/dia e as do Sudão atingem $0,1 \mathrm{~m}^{3}$ /operário.

Assim, é possível dispor de uma metodologia de desdobro de toras que envolva a classificação destas e o estabelecimento de modelos de corte para diferentes classes diamétricas envolvendo um programa de computador que resulte na otimização da produção.

Conduziu-se esta pesquisa, com o objetivo de avaliar a eficiência operacional da serraria na produção de madeira serrada de Pinus elliottii, envolvendo uma comparação entre o desdobro convencional e o desdobro programado.

\section{MATERIAL E MÉTODOS}

\subsection{Local do experimento e descrição da serraria}

O trabalho foi realizado numa serraria de uma empresa localizada no Município de Campina Grande do Sul, no Estado do Paraná. A empresa é composta por uma serraria e uma unidade de beneficiamento da madeira. Essa empresa dedica-se à produção de produtos de madeira com maior valor agregado como caixilhos, rodapés, painéis EGP e outros produtos para a construção civil. Trata-se de uma serraria de pequeno porte, uma vez que a produção de madeira serrada é menor que $500 \mathrm{~m}^{3} / \mathrm{mês}$ de acordo com Vital (2008). Os equipamentos que compõem a linha incluem uma serra fita simples acoplada ao carro portatora que é acionado pelo operador a partir do painel de controle, uma serra fita horizontal de dois cabeçotes para resserragem, e uma serra circular múltipla de um eixo com três discos, sendo um móvel, para as operações de refilo. O lay-out que ilustra a disposição das máquinas é apresentado na Figura 1. A serraria apresenta baixo nível de automação, sendo que a operação dos equipamentos é dependente em parte da mão de obra. Sendo assim, a serraria operava com cinco funcionários. 


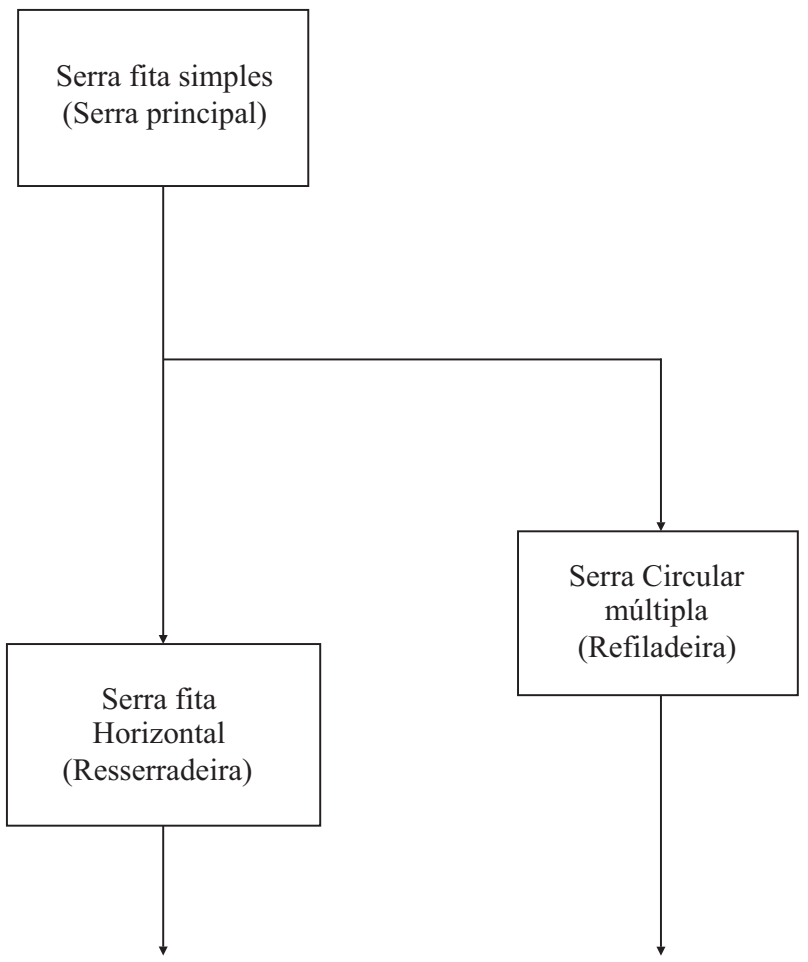

Figura 1 - Layout da serraria ilustrando a disposição das máquinas.

Figure 1-Layout of sawmill showing the machines arrangement.

\subsection{Espécie utilizada}

A espécie utilizada neste trabalho foi Pinus elliottii. A serraria recebia no seu pátio, toras com diâmetros entre $24 \mathrm{~cm}$ a $33 \mathrm{~cm}$ e com comprimento que variava de $2,55 \mathrm{~m}$ a 2,60 m. A mesma tinha um consumo médio mensal de 1.200 st de toras, o equivalente a $827,59 \mathrm{~m}^{3}$, considerando o fator de empilhamento de 1,45 para toras de $24 \mathrm{~cm}$ a 33 $\mathrm{cm}$ de diâmetro.

\subsection{Seleção de toras e classes diamétricas utilizadas}

No pátio de toras, foram selecionadas 80 toras que foram agrupadas em quatro classes diamétricas com base no diâmetro médio ou se o diâmetro da ponta fina fosse igual ou superior ao limite inferior da classe considerada, tendo resultado em 20 toras por classe diamétrica (Tabela 1). As toras selecionadas receberam um número de identificação e foram pintadas na ponta fina para facilitar o controle no rastreamento desde o pátio até ao final da linha de produção.
Tabela 1 - Número de toras selecionadas por classe diamétrica.

Table 1 - Quantity of logs selected by diametric class.

\begin{tabular}{cccc}
\hline $\mathrm{N}^{\mathrm{o}}$ & $\begin{array}{c}\text { Classe diamétrica } \\
(\mathrm{cm})\end{array}$ & $\begin{array}{c}\mathrm{N}^{\mathrm{o}} \text { de toras } \\
\text { selecionadas }\end{array}$ & $\begin{array}{c}\text { Comprimento } \\
(\mathrm{m})\end{array}$ \\
\hline 1 & $24,0-26,0$ & 20 & $2,55-2,60$ \\
2 & $26,1-28,0$ & 20 & $2,55-2,60$ \\
3 & $28,1-30,0$ & 20 & $2,55-2,60$ \\
4 & $30,1-33,0$ & 20 & $2,55-2,60$ \\
\hline Total & & 80 & \\
\hline
\end{tabular}

\subsection{Obtenção do volume de toras}

Para o cálculo do volume de toras foram tomadas as medidas da circunferência na ponta fina e ponta grossa de cada tora selecionada. Pela divisão da medida de circunferência com o $\pi$ foi obtido o diâmetro da ponta fina e o diâmetro da ponta grossa e a média aritmética destes, resultou no diâmetro médio. A partir desses dados, foi calculado o volume de cada tora, usando-se a seguinte equação:

$V=\frac{\pi^{*} D^{2}}{40000} * L$

Onde:

$\mathrm{V}=$ Volume da tora $\left(\mathrm{m}^{3}\right)$;

$\mathrm{D}=$ Diâmetro médio da tora $(\mathrm{cm})$;

$\mathrm{L}=$ Comprimento da tora $(\mathrm{m})$.

\subsection{Sistemas de desdobro usados}

As toras representantes de cada classe diamétrica foram separadas em dois lotes com 10 unidades. O primeiro lote foi submetido ao sistema convencional de desdobro adotado pela empresa e o segundo lote foi desdobrado de acordo com o modelo de corte pré-estabelecido com base no programa MaxiTora para a classe diamétrica correspondente.

As toras foram desdobradas nos dois sistemas para obter peças de madeira serrada com várias dimensões que incluem $42 \mathrm{~mm} \mathrm{X} 80 \mathrm{~mm}, 42 \mathrm{~mm} \mathrm{X} 120 \mathrm{~mm}, 42 \mathrm{~mm} \mathrm{X}$ $150 \mathrm{~mm}, 42 \mathrm{~mm}$ X $180 \mathrm{~mm}, 22 \mathrm{~mm}$ X $80 \mathrm{~mm}$ e $22 \mathrm{~mm} \mathrm{X}$ $160 \mathrm{~mm}$. Essas peças de madeira constituíam a linha de produtos da serraria.

No sistema convencional, as toras foram desdobradas de acordo com os critérios da empresa sem que houvesse alguma intervenção nas operações. O sistema de desdobro predominantemente utilizado foi do tipo

Cerne, Lavras, v. 19, n. 2, p. 339-346, abr./jun. 2013 
tangencial sucessivo, em que a tora era serrada em cortes paralelos uns aos outros, resultando em várias peças com faces planas, mas que requeriam o refilamento. $\mathrm{Na}$ Figura 2, é mostrado o esquema de desdobro utilizado na serraria.

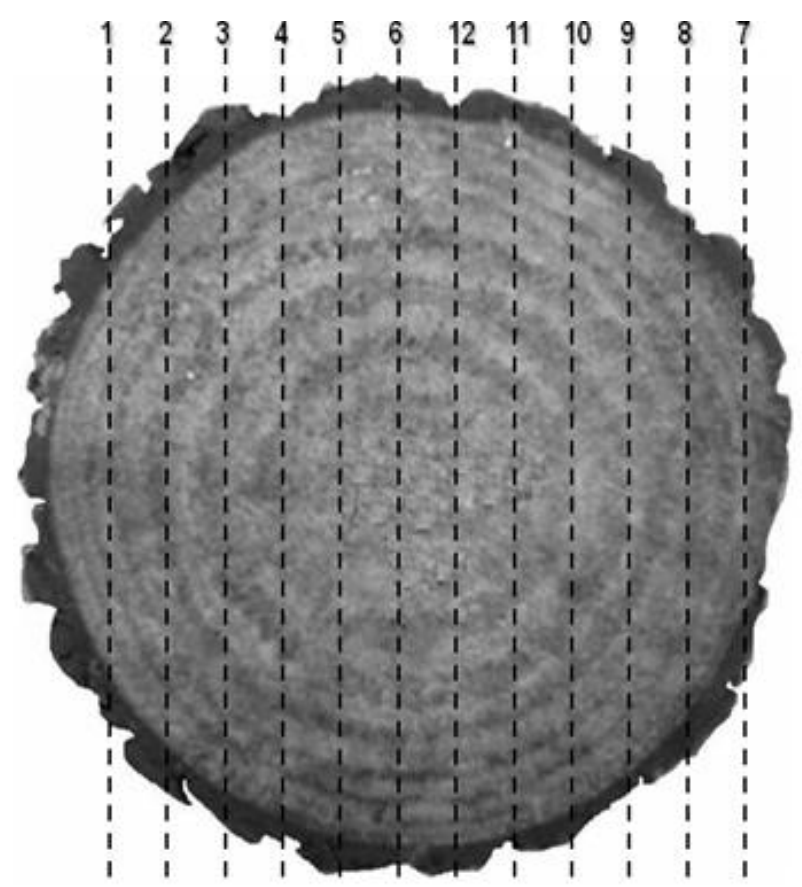

Figura 2 - Corte tangencial utilizado no desdobro convencional.

Figure 2-Tangential cut used in the conventional cut method.

No sistema programado, foi usado o diâmetro médio da classe para gerar o modelo de corte correspondente. Cada tora foi desdobrada de acordo com o modelo de corte da classe diamétrica correspondente (Figura 3). As toras passavam pela serra principal, definindo-se as espessuras finais e, em seguida, passavam pela refiladeira proporcionando às peças a largura final.

\subsection{Determinação da eficiência operacional da serraria}

A eficiência operacional é medida pela relação entre o volume de toras serradas por um determinado período ou turno e o número de operários envolvidos em todas as operações de desdobro (ROCHA, 2002).

A eficiência operacional dentro da classe diamétrica foi determinada com base na equação seguinte:

$$
E=\frac{480 * T}{t^{*} O}
$$

Cerne, Lavras, v. 19, n. 2, p. 339-346, abr./jun. 2013
Onde:

$\mathrm{E}=$ Eficiência operacional $\mathrm{em}^{3}$ por operário por turno;

$\mathrm{T}=$ Volume da tora $\mathrm{em}^{3}$ desdobrada;

$\mathrm{t}=$ Tempo em minutos de desdobro da tora;

$\mathrm{O}=$ Número de operários que trabalham dentro da serraria.

Para efeitos de cálculo da eficiência operacional, foi cronometrado o tempo de desdobro da tora desde a sua fixação no carro porta-tora até que a última peça de madeira serrada da tora fosse refilada. O tempo de trabalho na serraria por dia correspondeu a um turno de oito horas, equivalendo a 480 minutos. Este valor foi dividido pelo tempo gasto em minutos para desdobrar a tora, e o resultado foi multiplicado pelo volume da tora desdobrada, obtendo-se, desse modo, o volume da tora por turno. Em seguida, esse valor foi dividido pelo número total de funcionários envolvidos nas operações de desdobro para obter o valor da eficiência em metro cúbico por operário por turno. A eficiência operacional para cada classe diamétrica foi obtida a partir da média dos valores da eficiência de conversão de cada tora em madeira serrada dentro de cada classe.

A eficiência operacional da serraria foi obtida a partir da média dos valores da eficiência operacional das classes diamétricas estudadas.

\subsection{Análise estatística}

Neste experimento, foi avaliada a variável eficiência operacional tanto para o desdobro convencional como para o desdobro programado. Para tal, foi escolhido o delineamento inteiramente ao acaso, onde as classes diamétricas foram designadas por tratamentos. Cada tratamento tinha dez repetições. Foi feita a análise de variância para verificar se os tratamentos causaram um efeito diferente na variável eficiência operacional em análise a $95 \%$ de probabilidade. O teste de comparação de médias (teste de Tukey) foi feito para discriminar as diferenças entre as médias dos tratamentos a $95 \%$ de probabilidade.

Para comparar as metodologias de desdobro (convencional e programado) em função da variável em análise, foi escolhido o delineamento inteiramente ao acaso, obedecendo a um esquema fatorial com dois fatores, onde o fator A foi designado por metodologia de desdobro com dois níveis (desdobro convencional e desdobro programado) e o fator B foi atribuído à classificação de toras com quatro níveis (Classes diamétricas 1, 2, 3 e 4). 


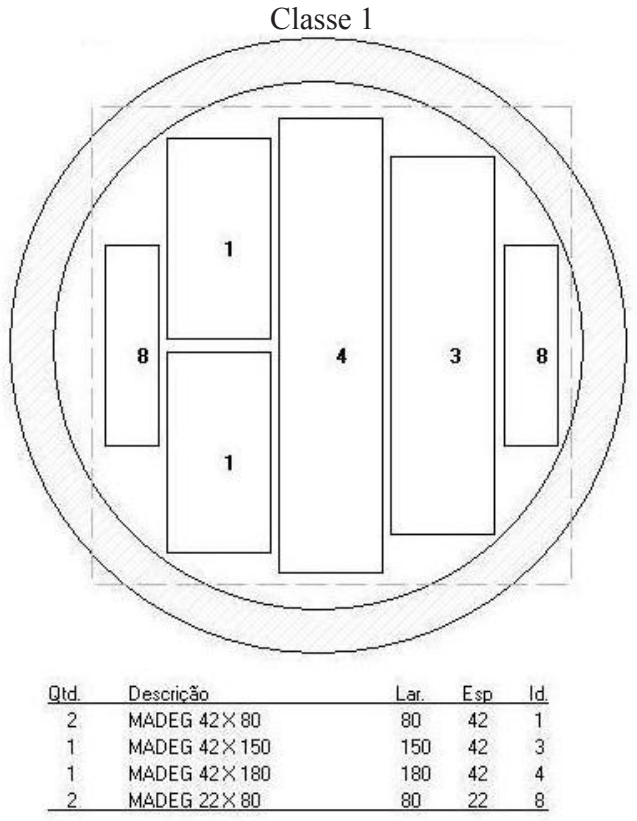

Diametro: 2500 Percentual de Aproveitamento: $49,10 \%$

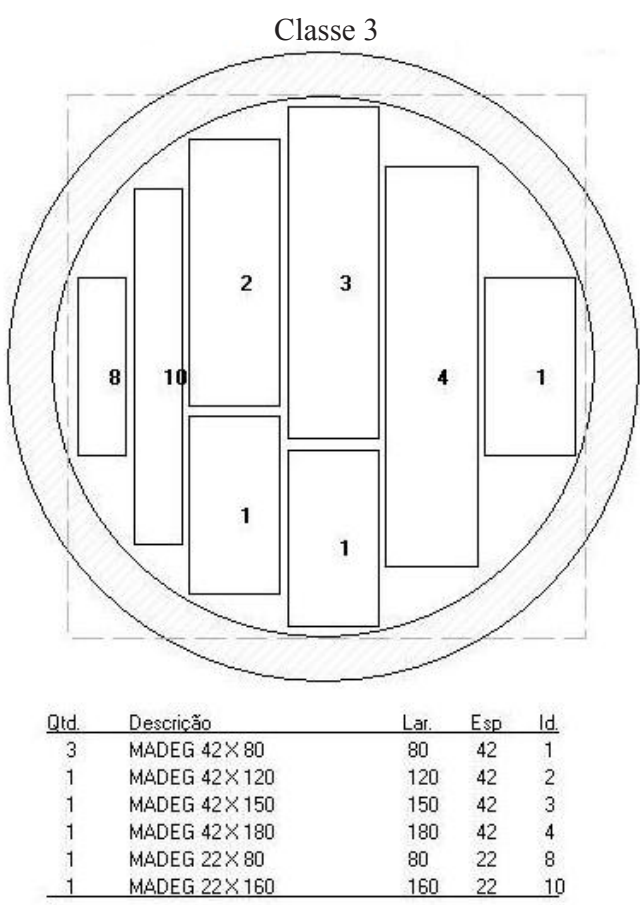

Diametro: 2910 Percentual de Aproveitamento: $51,51 \%$

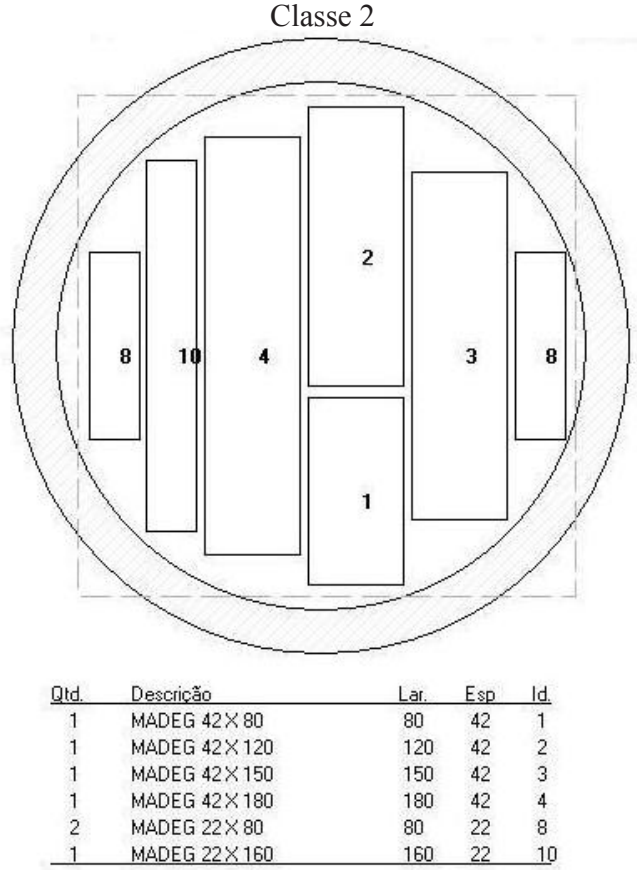

Diametro: 2710 Percentual de Aproveitamento: $50,80 \%$

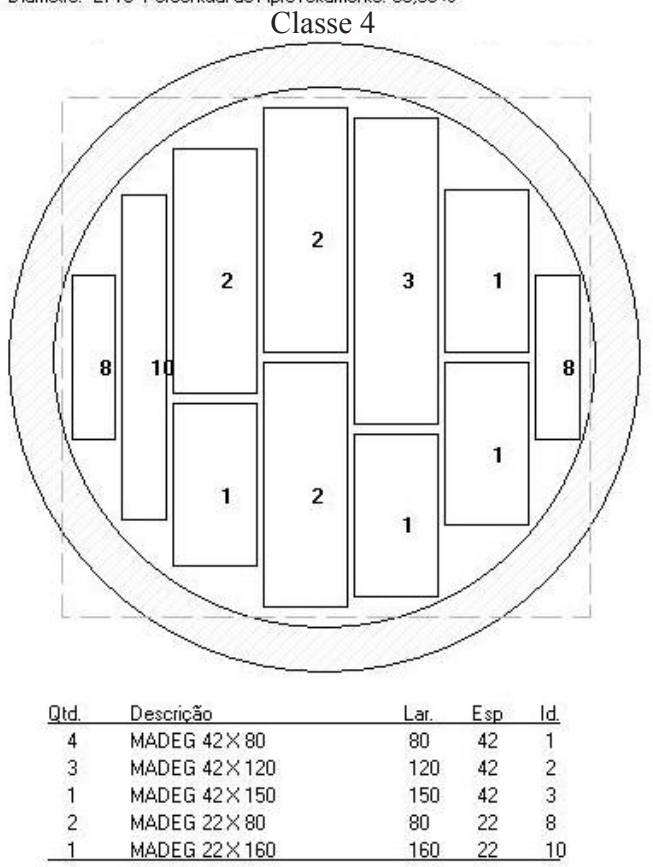

Diametro: 3160 Percentual de Aproveitamento: $53,43 \%$

Figura 3 - Modelos de corte estabelecidos para quatro classes diamétricas.

Figure 3-Cut models defined to four diametric classes.

Cerne, Lavras, v. 19, n. 2, p. 339-346, abr./jun. 2013 
Os resultados estatísticos foram obtidos a partir do programa de computador MSTAT-C, versão 2.10.

\section{RESULTADOS E DISCUSSÃO}

\subsection{Desdobro convencional}

Na Tabela 2, apresentam-se valores da eficiência operacional de desdobro convencional por classe diamétrica que variam de 9,71 a 11,22 m³/operário/turno, sendo a média geral correspondente a $10,18 \mathrm{~m}^{3} /$ operário/ turno.

Tabela 2 - Valores médios de eficiência operacional por classe diamétrica no desdobro convencional.

Table 2-Average values of operational efficiency per diametric class in the conventional cut process.

\begin{tabular}{ccc}
\hline $\begin{array}{c}\text { Classe } \\
\text { diamétrica }\end{array}$ & $\begin{array}{c}\text { Eficiência operacional } \\
\left(\mathrm{m}^{3} / \text { operário/turno }\right)\end{array}$ & $\begin{array}{c}\text { Coeficiente } \\
\text { de variação }(\%)\end{array}$ \\
\hline 1 & $9,71 \mathrm{a}$ & 5,54 \\
2 & $9,74 \mathrm{a}$ & 7,46 \\
3 & $10,05 \mathrm{a}$ & 8,68 \\
4 & $11,22 \mathrm{~b}$ & 8,77 \\
\hline
\end{tabular}

Média geral $\quad 10,18$

Médias seguidas pela mesma letra não diferem estatisticamente entre si pelo teste de Tukey a 95\% de probabilidade.

Na Tabela 2, pode ser observado que não houve diferenças significativas nos valores médios da eficiência operacional entre as classes 1, 2 e 3 a $95 \%$ de probabilidade. Esta igualdade estatística sugere que a eficiência operacional alcançada no desdobro de toras que fazem parte das classes 1, 2 e 3 toma um valor médio não diferente. Por outro lado, o valor da eficiência operacional para a classe 4 revelou ser estatisticamente superior e diferente a $95 \%$ de probabilidade em relação aos valores das demais classes.

\subsection{Desdobro programado}

Na Tabela 3, apresentam-se valores da eficiência operacional de desdobro programado por classe diamétrica que variam de 7,78 a $8,99 \mathrm{~m}^{3} /$ operário/turno, sendo a média geral correspondente a $8,07 \mathrm{~m}^{3} /$ operário/turno.

$\mathrm{O}$ teste de tukey demonstrou que não houve diferenças significativas a $95 \%$ de probabilidade nos valores médios de eficiência operacional entre as classes 1,2 e 3 . Entretanto, registraram-se diferenças significativas nos valores da eficiência operacional entre a classe $4 \mathrm{e}$
Tabela 3 - Valores médios de eficiência operacional por classe diamétrica no desdobro programado.

Table 3 - Average values of operational efficiency per diametric class in the programmed cut process.

\begin{tabular}{ccc}
\hline $\begin{array}{c}\text { Classe } \\
\text { diamétrica }\end{array}$ & $\begin{array}{c}\text { Eficiência Operacional } \\
\left(\mathrm{m}^{3} / \text { operário/turno }\right)\end{array}$ & $\begin{array}{c}\text { Coeficiente } \\
\text { de variação }(\%)\end{array}$ \\
\hline 1 & $7,78 \mathrm{a}$ & 15,07 \\
2 & $7,52 \mathrm{a}$ & 7,98 \\
3 & $8,01 \mathrm{ab}$ & 4,34 \\
4 & $8,99 \mathrm{~b}$ & 11,87 \\
\hline Média geral & 8,07 & \\
\hline
\end{tabular}

Médias seguidas pela mesma letra não diferem estatisticamente entre si pelo teste de Tukey a $95 \%$ de probabilidade.

as classes 1 e 2. Pelos resultados da Tabela 3, pode-se observar a tendência de aumento dos valores da eficiência operacional com o aumento do diâmetro da tora.

A eficiência operacional média geral obtida na serraria pelo desdobro programado foi de $8,07 \mathrm{~m}^{3} /$ operário/turno. Assim, a serraria fazendo o desdobro programado pode ser enquadrada no grupo de serrarias comuns de acordo com a classificação mencionada por Rocha (2002).

\subsection{Comparação entre o desdobro convencional e o desdobro programado}

A análise de variância da eficiência operacional revelou que a interação dos fatores metodologia de desdobro de toras e classificação de toras por classes diamétricas testadas não foi significativa, indicando que são independentes. Os fatores principais metodologia de desdobro de toras e classificação diamétrica apresentaram diferenças estatisticamente significativas a $95 \%$ de probabilidade. Os resultados de teste de comparação de médias da eficiência operacional da serraria para cada método de desdobro de toras e classes diamétricas estudados são apresentados na Tabela 4.

Na Tabela 4, pode ser observado que o teste de Tukey revelou que na classe diamétrica 4 , a eficiência operacional alcançada foi estatisticamente superior e diferente das demais classes. O teste de Tukey também revelou que a eficiência operacional alcançada na serraria pelo método de desdobro programado foi estatisticamente menor em relação à eficiência operacional obtida a partir do desdobro convencional. Esse resultado, foi contrário ao esperado, pois era suposto que pelo desdobro programado a eficiência operacional alcançada ao desdobrarem-se toras fosse maior. 
Tabela 4 - Comparação de médias de eficiência operacional entre o desdobro convencional e programado.

Table 4-Comparison of average operational efficiency between conventional and programmed sawing process.

\begin{tabular}{cccc}
\hline \multirow{2}{*}{$\begin{array}{c}\text { Classe } \\
\text { diamétrica }\end{array}$} & \multicolumn{2}{c}{$\begin{array}{c}\text { Eficiência operacional } \\
\left(\mathrm{m}^{3} / \text { operário/turno }\right)\end{array}$} & $\begin{array}{c}\text { Média de } \\
\text { eficiência da } \\
\text { classe }\end{array}$ \\
\cline { 2 - 3 } $\begin{array}{c}\text { Desdobro } \\
\text { convencional }\end{array}$ & $\begin{array}{c}\text { Desdobro } \\
\text { programado }\end{array}$ & \\
\hline 1 & 9,71 & 7,78 & $8,74 \mathrm{a}$ \\
2 & 9,74 & 7,52 & $8,63 \mathrm{a}$ \\
3 & 10,05 & 8,01 & $9,03 \mathrm{a}$ \\
4 & 11,22 & 8,99 & $10,10 \mathrm{~b}$ \\
\hline Média geral & $10,18 \mathrm{~A}$ & $8,07 \mathrm{~B}$ & \\
\hline
\end{tabular}

Médias seguidas da mesma letra maiúscula na horizontal e minúscula na vertical não diferem estatisticamente entre si pelo teste de Tukey a 95\% de probabilidade.

Nas operações de desdobro programado, os operadores da serra principal e refiladeira retiravam peças de madeira de acordo com o modelo de corte da classe diamétrica correspondente. Essas ações contribuíram para o aumento da eficiência operacional de conversão de toras na serraria, pois o operador da serra principal já não tomava decisões a cada instante no ato de desdobro. No entanto, alguns aspectos como a falta de experiência do operador da serra principal contribuiu para a queda da eficiência operacional da serraria. $\mathrm{O}$ operador levava mais tempo para desdobrar uma tora de acordo com o modelo de corte. Os tempos efetivos de desdobro de toras com base no modelo de corte foram relativamente altos quando comparados aos tempos efetivos do desdobro convencional, resultando em diminuição da eficiência de conversão de toras em madeira serrada.

A falta de sincronia entre os operadores da serra principal e refiladeira também contribuiu para alargar os tempos efetivos de desdobro da tora, resultando em queda da eficiência operacional. Para todas as classes diamétricas analisadas, com relação aos valores médios da eficiência operacional obtida a partir do desdobro convencional ao desdobro programado, houve uma diminuição em cerca de $2 \mathrm{~m}^{3}$ /operário/turno.

Na Figura 4, pode-se observar que para o desdobro convencional assim como para o desdobro programado, as classes 1, 2 e 3 apresentaram um comportamento homogêneo na eficiência operacional de desdobro. No entanto, foi verificado o aumento significativo da eficiência operacional na classe diamétrica 4 para ambas as metodologias de desdobro.

De um modo geral, no desdobro programado o fator humano caracterizado pela falta de experiência na utilização dos modelos de corte resultou em queda de eficiência operacional nas operações de desdobro. Entretanto, a experiência dos operadores torna-se relevante para que, efetivamente, o programa MaxiTora seja aplicado melhor na serraria e surta os efeitos esperados.

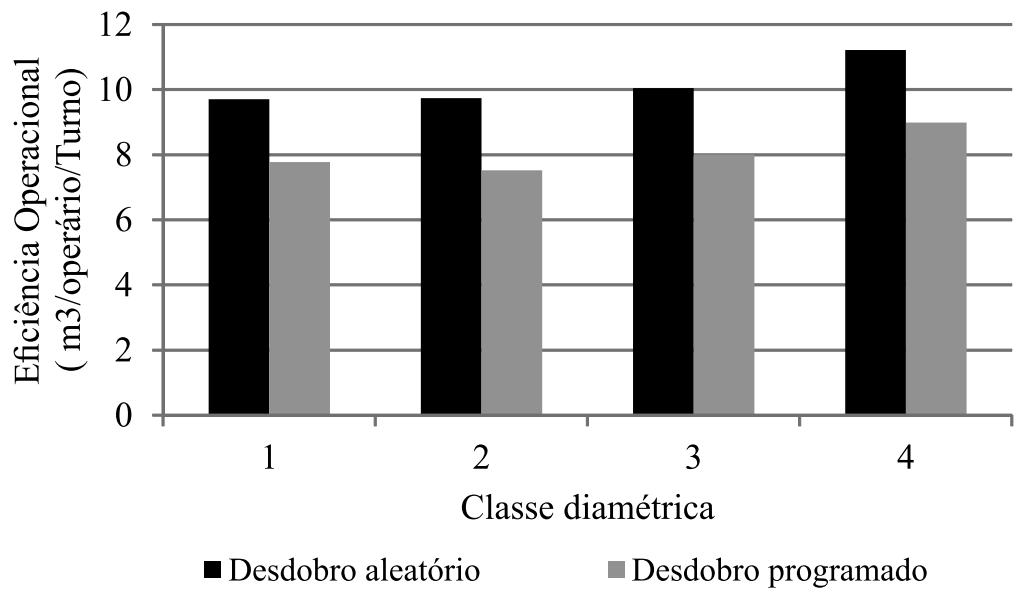

Figura 4 - Gráfico de comparação de médias de eficiência operacional por classe diamétrica entre os desdobros convencional e programado.

Figure 4 - Graphics of comparison of average operational efficiency per diametric class between conventional and programmed cut process.

Cerne, Lavras, v. 19, n. 2, p. 339-346, abr./jun. 2013 
É importante ressaltar que a falta de experiência dos operadores das máquinas pode ser resolvido pelo treinamento dos mesmos visando à sua melhor adaptação aos modelos de corte no desdobro de toras resultando em melhoria na eficiência operacional.

\section{CONCLUSÕES}

De acordo com os resultados obtidos, concluiu-se que:

- Os valores da eficiência no desdobro de toras aumentaram com o aumento do diâmetro da tora, mantendo constantes outros fatores como o tempo de desdobro.

- A eficiência média geral da serraria, alcançada pelo desdobro programado, foi menor em relação à eficiência média geral alcançada com o desdobro convencional.

- A eficiência da serraria, alcançada no desdobro programado, foi reduzida pela falta de treinamento dos operadores das máquinas.

\section{REFERÊNCIAS}

ASSOCIAÇÃO BRASILEIRA DA INDÚSTRIA DE MADEIRA PROCESSADA. Estudo setorial 2007: indústria de madeira processada mecanicamente: ano base 2006. Curitiba, 2007. $40 \mathrm{p}$.
ASSOCIAÇÃO BRASILEIRA DE PRODUTORES DE FLORESTAS PLANTADAS. Anuário estatístico da ABRAF 2012: ano base 2011. Brasília, 2012. 149 p.

BATISTA, D.; CARVALHO, A. M. Avaliação do desempenho operacional de uma serraria através do estudo do tempo, rendimento e eficiência. Scientia Florestalis, Piracicaba, n. 75, p. 31-38, set. 2007.

HAYGREEN, J. G.; BOWER, J. L. Forest products and wood science: an introduction. Ames: Iowa State University, 1982. $495 \mathrm{p}$.

ROCHA, M. P. da. Técnicas de planejamento em serrarias. Curitiba: FUPEF, 2002. 121 p. (Série Didática FUPEF, 02/01).

TSOUMIS, G. Science and technology of wood: structure, properties, utilization. New York: Chapman \& Hall, 1991. 494 p.

VITAL, B. R. Planejamento e operação de serrarias. Viçosa, MG: UFV, 2008. 211 p.

WILLISTON, M. Lumber manufacturing: the design and operation of sawmills and planer mills. San Francisco: M. Freeman, 1978.

Cerne, Lavras, v. 19, n. 2, p. 339-346, abr.jun. 2013 